Open Access

\title{
Is minimally invasive esophagectomy effective for preventing anastomotic leakages after esophagectomy for cancer? A systematic review and meta-analysis
}

\author{
Can Zhou', Gang $\mathrm{Ma}^{1}$, Xiao $\mathrm{Li}^{1}$, Juan $\mathrm{Li}^{2}$, Yu Yan' ${ }^{1}$, Peijun $\mathrm{Liu}^{2}$, Jianjun $\mathrm{He}^{1 *}$ and Yu Ren ${ }^{1 *}$
}

\begin{abstract}
Background: Compared with open esophagectomy (OE), minimally invasive esophagectomy (MIE) proves to have clear benefits in reducing the risk of pulmonary complications for patients with resectable esophageal cancer. The objectives of our study were to explore the superiority of MIE in reducing the occurrence of anastomotic leakages (ALs) when compared to OE.
\end{abstract}

Methods: A systematic review and meta-analysis was performed to assess the superiority of MIE on the occurrence of ALs over OE, by searching many sources (through December, 2014) such as Medline, Embase, Wiley Online Library, and Cochrane Library. Fixed-effects model was used to calculate summary odds ratios (ORs) to quantify associations between OE and MIE groups. Cochran's $Q$ and $P^{2}$ statistics were used to evaluate heterogeneity among studies.

Results: Among a total of 43 studies involving 5537 patients included in the meta-analysis, 2527 (45.6 \%) cases underwent MIE and 3010 (54.4\%) cases underwent OE. Compared to patients undergoing OE, patients undergoing MIE did not have statistical significance in reduced occurrence of ALs (OR $=0.97,95 \% \mathrm{Cl}=0.80-1.17)$. Insignificant reduced occurrence of ALs was not associated with anastomotic location $(\mathrm{OR}=0.90,95 \% \mathrm{Cl}=0.71-1.13)$ or anastomotic procedure $(\mathrm{OR}=1.02,95 \% \mathrm{Cl}=0.79-1.30)$.

Conclusions: More proofs are needed to clarify the strengths or weaknesses of MIE in preventing anastomotic leakages after esophagectomy for cancer. A largely randomized, controlled trial should be undertaken to resolve this contentious issue urgently.

Keywords: Minimally invasive esophagectomy, Open esophagectomy, Anastomotic leakages

\section{Background}

Esophagectomy is a primary curative modality for localized esophageal cancer. Esophagogastric anastomotic leakage (AL) is a devastating complication of esophageal resection and is associated with serious patient morbidity and mortality [1-3]. The reported incidence of ALs accounts for $40 \%$ of postoperative fatalities after esophagectomy, with the frequency ranged from 4 to $17 \%[2,4,5]$. Although the etiology of ALs is

\footnotetext{
*Correspondence: chinahjj@163.com; renyyyyy@126.com

'Department of Breast Surgery, the First Affiliated Hospital, Xi'an Jiaotong University, 277 Yanta Western Rd, Xi'an 710061 Shaanxi Province, China Full list of author information is available at the end of the article
}

multifactorial, anastomotic technical errors and occult ischemia of the mobilized gastric fundus are the two major causes $[1,6]$. Thus, choosing what surgical technique is supposed to play a major role. For example, esophagogastric anastomoses after esophagectomy can be performed in the neck or chest, by a hand-sewn method or by using a mechanical stapling device $[7,8]$.

Minimally invasive esophagectomy (MIE), which was first described in the 1990s [9-11], was attributed to the superiority on a reduced risk of postoperative outcomes without compromising oncological outcomes, avoiding thoracotomy and laparotomy [12-17]. Therefore, theoretically, the procedure of MIE may have a significant 
impact on the reduction in ALs risk due to the introduction of long laparoscopic and thoracoscopic instruments. Nevertheless, after scrutinizing pertinent original research articles and randomized controlled trials, we found that this theoretical assumption has never been subjected to empirical verification. The main reason for this might be that previous studies focused too much on efficacy and safety rather than surgical techniques.

Therefore, at least two critical questions are of considerable interest and remain unanswered in esophageal surgery: (i) whether MIE has superiority in reducing the occurrence of ALs when compared to open esophagectomy (OE) and (ii) whether the anastomotic methods or sites of MIE have effect on prevention of ALs. For this, we conducted the present systematic review and metaanalysis to comprehensively explore the relation between ALs and MIE, as well as ALs and the concomitant anastomotic methods or sites, aiming to provide meaningful clues for future research and current clinical practice.

\section{Methods}

Literature search

Two independent observers searched the following databases in Medline, Embase, Wiley Online Library, and other sources such as the Cochrane Library from inception to December 15, 2014. The databases were searched using the terms minimally invasive esophagectomy, esophageal cancer, esophageal carcinoma, and open esophagectomy. This report complies with the preferred reporting items for systematic reviews and meta-analyses (PRISMA) [18].

\section{Study selection}

Studies were selected for inclusion if they met the following criteria: (i) comparing MIE with OE, (ii) published in English or Chinese, (iii) randomized or nonrandomized controlled study with parallel controls, and (iv) gray literatures such as conference proceedings, reports, and other peer-reviewed research.

The following studies were excluded: (i) interest was not reported or it was impossible to calculate the outcomes from the published results, (ii) not mentioning a distinct group of patients or comparing the outcomes of interest, and (iii) review articles, letters, comments, case reports, and unpublished articles (abstracts only).

\section{Quality assessment and data collection}

The methodological quality of the included studies was independently assessed by two observers using the methodological index for non-randomized studies (MINORS) instrument, a quality assessment tool specifically developed for systematic reviews of non-randomized control studies [19]. The total quality score ranges from 0 (low quality) to 24 (high quality). The disagreements between the two observers were resolved by discussion with the corresponding author via e-mail or personal interview.

The information, extracted from each publication in the form of a table, included the following: authors, the nation of origin, the year of publication, the number and ages of the patients, etc. All eligible studies were retrieved and evaluated by two independent reviewers. Disagreements on inclusion were discussed with the guidance of the corresponding author via e-mail, if necessary.

\section{Outcomes definition}

The definition of minimally invasive esophagectomy (MIE) is totally MIE, not including thoracoscopic/laparotomy assisted esophagectomy, or hybrid MIE. Anastomotic leakages, leak, and fistula uniformly referred to ALs.

\section{Statistical analysis}

The primary outcome measure was ALs, as it was considered an important outcome indicator in esophageal surgery and had been used to compare outcomes among different medical institutions. Secondary outcome included the association of ALs and anastomotic sites or methods for patients under MIE.

After appropriate conversion, data from the various studies were combined using fixed-effects meta-analyses. Forest plots were provided with pooled odds ratios (ORs) and corresponding $95 \%$ confidence intervals (CIs). Begg's funnel plot was used to provide diagnosis of the potential publication bias [20]. Cochran's chisquare-based $Q$ statistic test was performed in order to assess possible heterogeneity between the individual studies and thus to ensure that each group of the studies was suitable for meta-analysis [21].Thresholds for interpretation of heterogeneity were adopted as outlined in the Cochrane Handbook: 0 to $40 \%$-low, 30 to $60 \%$ moderate, 50 to $90 \%$-possible substantial, and 75 to $100 \%$-considerable heterogeneity. If the heterogeneity was high $[22]\left(I^{2}>50 \%\right.$ or $\left.P<0.10\right)$, a sensitivity analysis would be performed using the "metaninf" Stata command. If the heterogeneity was deemed to be considerable, we would not pool the results and provide a narrative assessment instead [23].All statistical processes were done in Stata version 12.0 (Stata Corp LP, College Station, TX, USA) software.

\section{Results}

\section{Selected studies and methodological quality}

Figure 1 shows a flow diagram of our search and selection process. Forty-four studies were selected from the 57 studies, with the reason that 13 studies did not compare the outcomes of ALs. The evaluation results of the methodological quality of the studies are shown in 


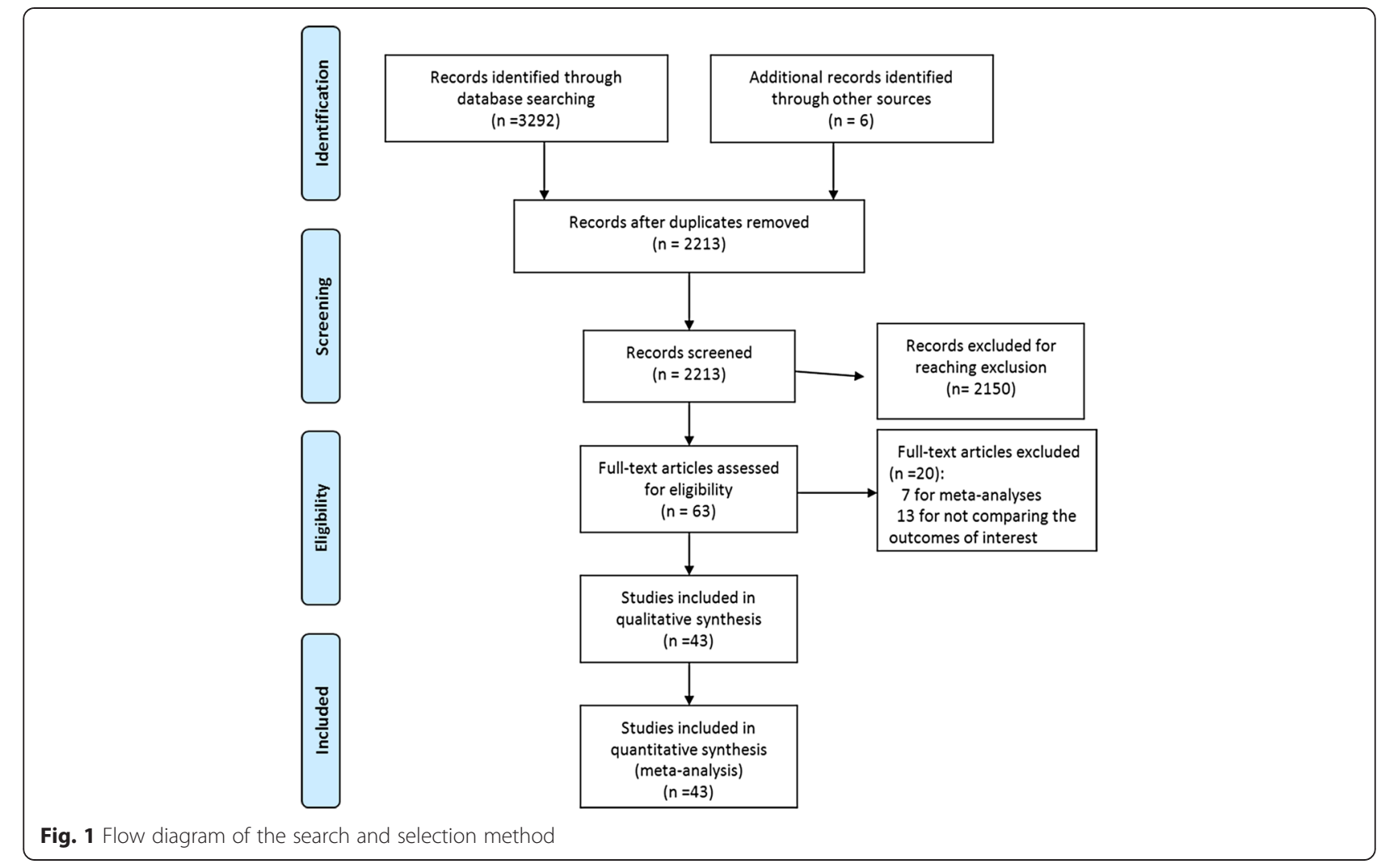

Table 1 . The total quality scores of the included studies ranged from 16 to 20 (Table 1). Randomized controlled design was done in only one study [13].

\section{Characteristics of studies}

The selected trials included a total of 43 studies and 5537 patients (Table 1). Among the included 43 studies, 19 were retrospective studies [15, 24-41], 13 were prospective ones [14, 42-53], and only 1 was randomized controlled trial (RCT) [13]. Ten studies were done in Japan [25, 28, 29, 35, 43, 44, 50, 52, 54, 55], 9 in USA [14, 24, 27, 33, 41, 46, 51, 56, 57], 7 in China $[31,36,38-40,58,59], 5$ in the UK $[47,49,53,60,61], 3$ in Netherlands $[15,34,62], 3$ in Australia [42, 48, 63], 2 in Italy $[45,64]$, and the remaining were conducted in Germany [30], Chile [26], Belgium [32], and Finland [37].

\section{Type of surgery}

Data for ALs were available for 43 studies totaling 5537 patients, of whom 2527 (45.6\%) patients underwent MIE and 3010 (54.4 \%) underwent OE, with an overall ALs rate of $9.2 \%(509 / 5537)$. The pooled OR of 0.97 (95\% CI $=0.80-1.17)$, as shown in Fig. 2, indicated no significant reduction in the risk of ALs after MIE when compared with $\mathrm{OE}$, with no heterogeneity among results from different studies $\left(I^{2}=0.0 \%, P=0.564\right)$.

\section{Anastomotic location of MIE}

The analysis on anastomotic location of MIE on ALs status was based on 34 trials or 4005 participants. An insignificant effect of the anastomotic location of MIE in ALs status $(\mathrm{OR}=0.90,95 \% \mathrm{CI}=0.71-1.13)$ was showed in Fig. 3, with no statistical heterogeneity $\left(I^{2}=0.00, P=0.771\right)$.

Twenty-eight studies, including a total of 3078 patients, had cervical anastomosis as anastomotic location for MIE, with an overall rate of $9.0 \%(278 / 3078)$. The summary OR 0.84 , as shown in Fig. 3, indicated that no significant reduction of 14 cases per 1000 individuals treated with MIE (95 \% CI $=0.65-1.09$ ) when compared with $\mathrm{OE}$, with no heterogeneity among results from different studies $\left(I^{2}=0.0 \%, P=0.791\right)$.

The remaining 6 studies totaling 927 patients went through thoracic anastomosis as anastomotic location for MIE, with an overall ALs rate of $6.6 \%$ (61/927). However, fix-effects pooled analysis (OR $=1.14,95 \% \mathrm{CI}=0.69$ 1.70) suggested that the incidence of ALs was not significantly higher when compared with $\mathrm{OE}(33 / 449,7.3$ vs. $5.8 \%, 28 / 478)$, with no heterogeneity among results from different studies $\left(I^{2}=6.1 \%, P=0.377\right)$, as shown in Fig. 3 .

\section{Anastomotic procedure of MIE}

The analysis on anastomotic procedure of MIE on ALs status was based on 27 trials totaling in 3478 participants. No statistical significance effect of anastomotic procedure of 
Table 1 Characteristics and demographics of included studies

\begin{tabular}{|c|c|c|c|c|c|c|c|c|c|c|c|}
\hline \multirow[t]{2}{*}{ Study } & \multirow[t]{2}{*}{ Year } & \multirow[t]{2}{*}{ Country } & \multirow[t]{2}{*}{ Design } & \multicolumn{2}{|c|}{ Cases } & \multicolumn{2}{|l|}{ ALS } & \multirow[t]{2}{*}{ MINORS } & \multirow[t]{2}{*}{ Adeno. \% } & \multicolumn{2}{|l|}{ Anastomosis } \\
\hline & & & & $\overline{M I E}$ & $\mathrm{OE}$ & $\overline{M I E}$ & $\mathrm{OE}$ & & & Location & Procedures \\
\hline Smithers BM [42] & 2007 & Australia & $P$ & 23 & 114 & 1 & 10 & 20 & 70.6 & Cervical & Hand-sewn \\
\hline Kunisaki C [43] & 2004 & Japan & $P$ & 15 & 30 & 2 & 1 & 16 & NA & Intrathoracic & Stapler \\
\hline Law S [58] & 1997 & China & NA & 18 & 63 & 0 & 2 & 16 & NA & Cervical & Hand-sewn \\
\hline Nguyen NT [24] & 2000 & USA & $\mathrm{R}$ & 18 & 36 & 2 & 4 & 16 & NA & Cervical & Stapler and hand-sewn \\
\hline Kubo N [25] & 2014 & Japan & $\mathrm{R}$ & 93 & 74 & 6 & 7 & 16 & NA & Cervical & Unknown \\
\hline Osugi H [44] & 2003 & Japan & P & 72 & 77 & 1 & 2 & 20 & 0 & Cervical & Unknown \\
\hline Van den Broek WT [62] & 2004 & Netherlands & NA & 19 & 14 & 2 & 3 & 19 & 71.1 & Cervical & Hand-sewn \\
\hline Braghetto I [26] & 2005 & Chile & $\mathrm{R}$ & 47 & 60 & 3 & 10 & 20 & NA & Cervical & Hand-sewn \\
\hline Benzoni E [45] & 2006 & Italy & P & 9 & 13 & 1 & 1 & 20 & 23.8 & Cervical & Hand-sewn \\
\hline Fabian T [27] & 2006 & USA & $\mathrm{R}$ & 51 & 24 & 3 & 3 & 20 & 69.2 & Cervical and intrathoracic & Unknown \\
\hline Shiraishi T [28] & 2006 & Japan & $\mathrm{R}$ & 78 & 37 & 9 & 9 & 16 & NA & Cervical & Unknown \\
\hline Bresadola V [64] & 2007 & Italy & NA & 22 & 43 & 1 & 2 & 16 & NA & Cervical & Hand-sewn \\
\hline Perry KA [46] & 2009 & USA & P & 21 & 21 & 4 & 6 & 16 & 45.2 & Cervical & Unknown \\
\hline Parameswaran R [60] & 2009 & UK & NA & 50 & 30 & 4 & 1 & 19 & 82.5 & Cervical & Stapler \\
\hline Kitagawa H [54] & 2009 & Japan & NA & 16 & 10 & 1 & 2 & 20 & NA & Cervical & Hand-sewn \\
\hline Zingg U [63] & 2009 & Australia & NA & 56 & 98 & 11 & 11 & 20 & 72.1 & Cervical & Hand-sewn \\
\hline Saha AK [61] & 2009 & UK & NA & 16 & 28 & 2 & 3 & 19 & $16+$ & Cervical & Stapler and hand-sewn \\
\hline Hamouda AH [47] & 2010 & UK & P & 24 & 51 & 3 & 0 & 16 & 80 & Intrathoracic & Hand-sewn \\
\hline Wang H [59] & 2010 & China & NA & 27 & 29 & 5 & 4 & 16 & 5.3 & Cervical & Unknown \\
\hline Schoppmann SF [48] & 2010 & Australia & P & 31 & 31 & 1 & 8 & 20 & 46.8 & Cervical & Hand-sewn \\
\hline Pham TH [14] & 2010 & USA & $\mathrm{P}$ & 44 & 46 & 4 & 5 & 16 & 74.4 & Cervical and intrathoracic & Stapler \\
\hline Safranek PM [49] & 2010 & UK & $\mathrm{P}$ & 41 & 46 & 7 & 1 & 16 & NA & Cervical & Stapler and hand-sewn \\
\hline Tsujimoto H [29] & 2010 & Japan & $\mathrm{R}$ & 20 & 37 & 1 & 5 & 16 & NA & Cervical and intrathoracic & Stapler and hand-sewn \\
\hline Schröder W [30] & 2010 & Germany & $\mathrm{R}$ & 238 & 181 & 18 & 17 & 16 & 60.1 & Intrathoracic & Stapler \\
\hline Berger AC [56] & 2011 & USA & NA & 65 & 53 & 9 & 6 & 16 & 79.7 & Cervical & Stapler \\
\hline Yamasaki M [57] & 2011 & USA & NA & 109 & 107 & 6 & 4 & 16 & 79.7 & Cervical & Stapler \\
\hline Gao Y [31] & 2011 & China & $\mathrm{R}$ & 96 & 78 & 7 & 6 & 16 & 5.2 & Cervical & Hand-sewn \\
\hline Lee JM [50] & 2011 & Japan & $P$ & 30 & 64 & 2 & 18 & 20 & 5.1 & Cervical & Stapler and hand-sewn \\
\hline Nafteux P [32] & 2011 & Belgium & $\mathrm{R}$ & 65 & 101 & 5 & 10 & 16 & 75.3 & Cervical & Unknown \\
\hline Sundaram A [33] & 2012 & USA & $\mathrm{R}$ & 47 & 57 & 4 & 4 & 20 & 78.8 & Cervical & Unknown \\
\hline Sihag S [51] & 2012 & USA & P & 38 & 76 & 0 & 2 & 16 & 85.1 & Intrathoracic & Stapler \\
\hline Maas KW [34] & 2012 & Netherlands & $\mathrm{R}$ & 50 & 50 & 4 & 3 & 20 & 69 & Cervical & Hand-sewn \\
\hline Kinjo Y [52] & 2012 & Japan & P & 106 & 79 & 8 & 10 & 19 & 3.2 & Cervical & Unknown \\
\hline Tsujimoto H [35] & 2012 & Japan & $\mathrm{R}$ & 22 & 27 & 7 & 3 & & & Cervical and intrathoracic & Stapler \\
\hline Biere SS [15] & 2013 & Netherlands & $\mathrm{RCT}$ & 59 & 56 & 7 & 4 & 18 & 61.7 & Cervical and intrathoracic & Stapler \\
\hline Noble F [53] & 2013 & UK & $P$ & 53 & 53 & 5 & 2 & 19 & NA & Cervical and intrathoracic & Stapler \\
\hline Ichikawa H [55] & 2013 & Japan & NA & 153 & 162 & 14 & 27 & 20 & 66.7 & Cervical and intrathoracic & Hand-sewn \\
\hline Mu J [36] & 2014 & China & $\mathrm{R}$ & 176 & 142 & 12 & 4 & 16 & NA & Cervical & Stapler \\
\hline Kauppi J [37] & 2014 & Finland & $\mathrm{R}$ & 74 & 79 & 7 & 6 & 18 & NA & Intrathoracic & Hand-sewn \\
\hline Meng F [38] & 2014 & China & $\mathrm{R}$ & 94 & 89 & 6 & 7 & 18 & 3.2 & Cervical & Hand-sewn \\
\hline Zhang J [39] & 2014 & China & $\mathrm{R}$ & 60 & 61 & 3 & 2 & 16 & NA & Intrathoracic & Stapler \\
\hline Li J [40] & 2014 & China & $\mathrm{R}$ & 89 & 318 & 19 & 45 & 20 & 2.2 & Cervical and intrathoracic & Stapler and hand-sewn \\
\hline Javidfar J [41] & 2012 & USA & $\mathrm{R}$ & 92 & 165 & 5 & 7 & 18 & 91 & Cervical & Unknown \\
\hline
\end{tabular}




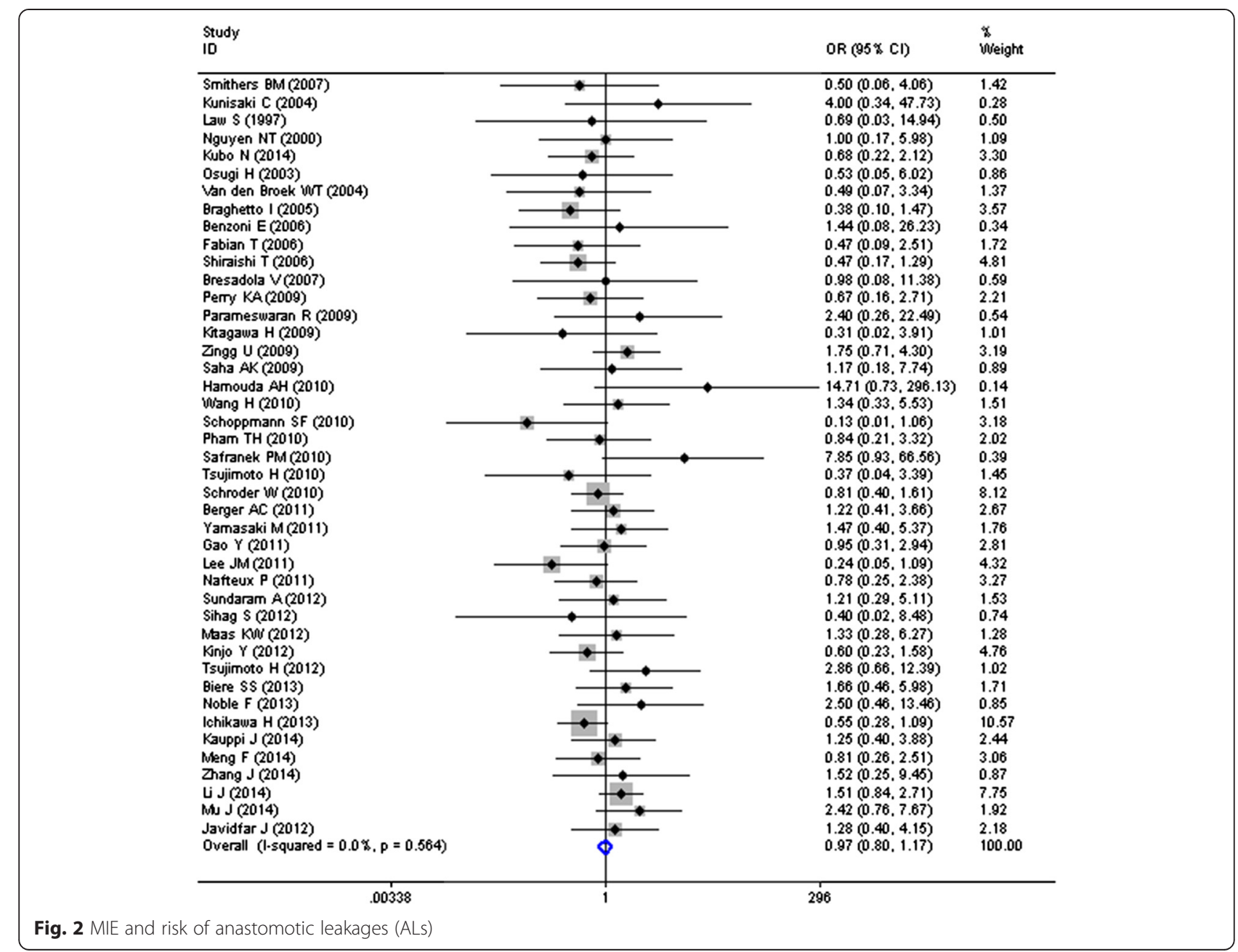

MIE in ALs status $(\mathrm{OR}=1.02,95 \% \mathrm{CI}=0.79-1.30)$ was showed in Fig. 3, with no statistical heterogeneity $\left(I^{2}=0.00\right.$, $P=0.539$ ).

Fifteen studies including 1687 cases had hand-sewn anastomosis as anastomotic procedure for MIE, with an overall rate of $9.5 \%(160 / 1687)$. However, as shown in Fig. 4, the pooled OR was 0.80 (95 \% CI=0.57-1.11) which indicated insignificant reduction of 18 cases per 1000 individuals treated with MIE (62/732, 8.5 vs. $10.3 \%$, 98/955), with no heterogeneity among results from different studies $\left(I^{2}=0.1 \%, P=0.448\right)$.

Twelve studies and 1791 cases investigated stapler anastomosis as anastomotic method for MIE, with an overall ALs rate of $7.1 \%$ (128/1791). The pooled OR was 1.36 (95 \% $\mathrm{CI}=0.94-1.97)$, showing insignificantly absolute decrease of 24 patients per 1000 individuals treated with MIE, with no heterogeneity $\left(I^{2}=0.0 \%, P=0.807\right)$, as shown in Fig. 4 .

\section{Publication bias and sensitivity analysis}

We plotted Begg's funnel plot (Fig. 5) to examine small study effects. We also used Begg's and Egger's weighted regression method to calculate $P$ values for bias. As shown in Fig. 5 the shape of the funnel plots did not reveal any evidence of obvious asymmetry. The $P$ values of the Egger's test were $0.869,0.578$, and 0.417 for type of surgery, anastomotic location of MIE, and anastomotic procedure of MIE, respectively, implying no existence of publication bias.

The influence of each study on the pooled ORs was examined by repeating the meta-analysis while sequentially omitting individual studies. Sensitivity analysis for type of surgery, anastomotic location of MIE, and anastomotic procedure of MIE indicated that no single study influenced the pooled ORs qualitatively, suggesting that the results of our meta-analysis are stable.

\section{Discussion}

In our systematic review and meta-analysis, data to study the superiority of MIE on the occurrence of ALs was assessed in 43 studies totaling 5537 patients. We showed in a comprehensive systematic review that the use of stapler anastomosis for MIE might be insignificantly associated with the occurrence of ALs when 


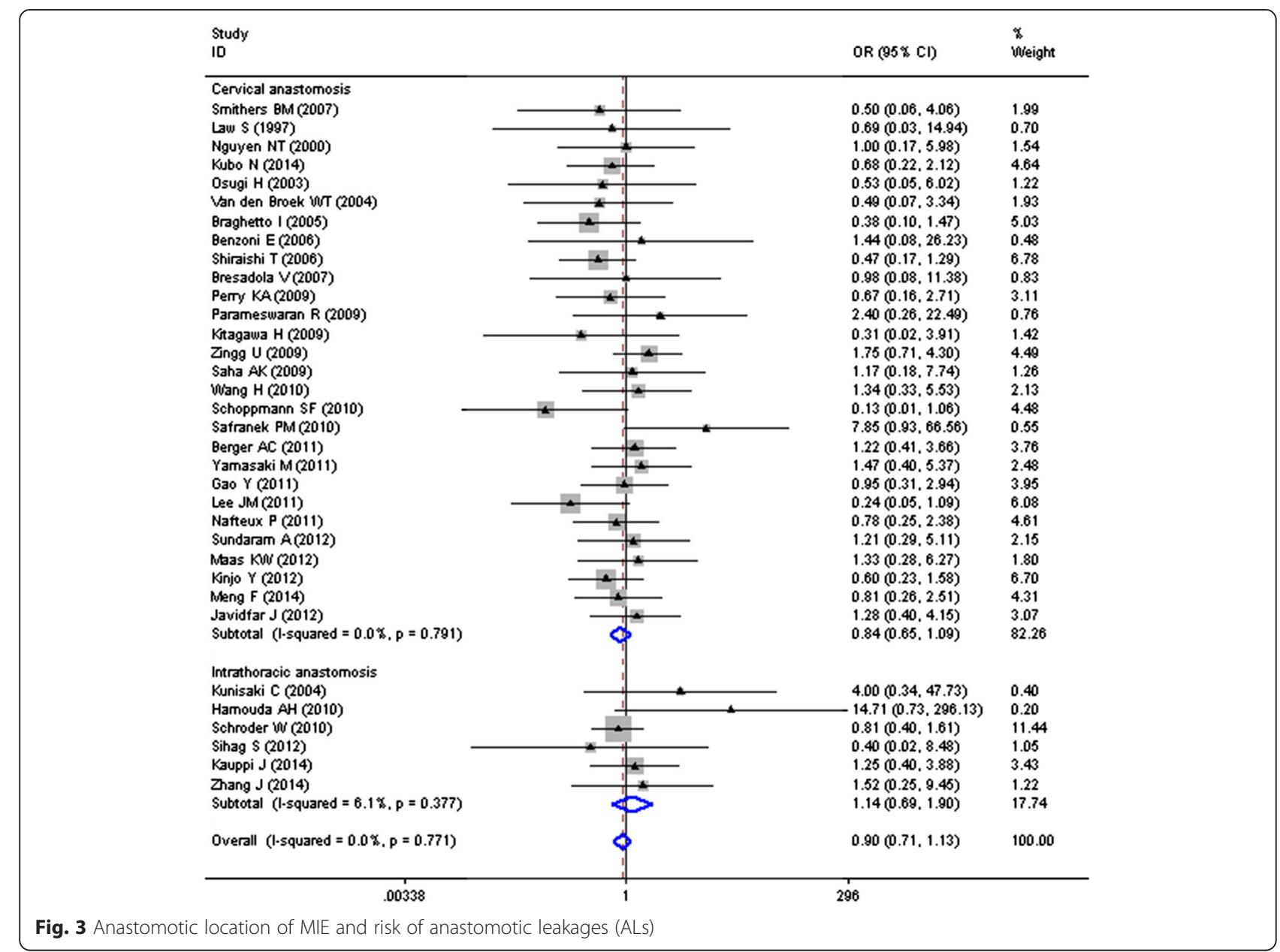

compared with OE, irrespective of anastomotic locations or procedures.

As we described previously, resection for carcinoma of the esophagus with gastric transposition is currently considered as the standard surgical treatment for cure or palliation of esophageal cancer patients. Stomach is used most commonly for restoring gastrointestinal continuity through esophagogastrostomy anastomosis [7, 8]. AL after esophageal resection for cancer is supposed to be a severe complication, which contributes to considerable mortality and poor healing quality. In our analysis, the occurrence of ALs was $9.2 \%$ (509/5537), which was consistent with the frequency 4-17 \% reported in the previous papers. The prevention of ALs appears quite important in clinical research. Anastomotic technical errors and occult ischemia of the mobilized gastric fundus were regarded as the two major causes in the etiology of ALs. In comparison with OE technique, we also found the AL rate tended to reduce after cervical anastomosis but increase after intrathoracic anastomosis. The result was inconsistent with the previous report that MIE was associated with an increased incidence of $\mathrm{AL}$ due to the traumatic handling of the gastric conduit and the pressure transmitted through rigid laparoscopic instruments during mobilization, which resulted in increased tissue ischemia $[65,66]$. The discrepancies could be attributed by the differences in the size and design of included studies.

The classical open approaches for esophageal resection include resection with a left thoracotomy, a thoracoabdominal resection approach and left neck, thoracoabdominal resection approach, also named as Sweet esophagectomy, Ivor Lewis esophagectomy, and McKeown-type esophagectomy. We know that esophagogastric anastomoses after esophagectomy can be performed in the neck for Sweet and Ivor Lewis approaches or the chest for three-incision approach [7, 8]. Moreover, whether the anastomosis should be performed in the neck or thorax is still a highly controversial issue in reconstruction after esophagectomy. Some authors favor anastomoses in the neck despite an increased incidence of leakage and damage to the recurrent laryngeal nerve due to better tumor eradication and reduced mortality and morbidity associated with an anastomotic breakdown $[67,68]$. Others favor thoracic anastomosis for a lower but more ominous leakage rate due to less esophagi removed but decreased margins [69]. Consequently, 


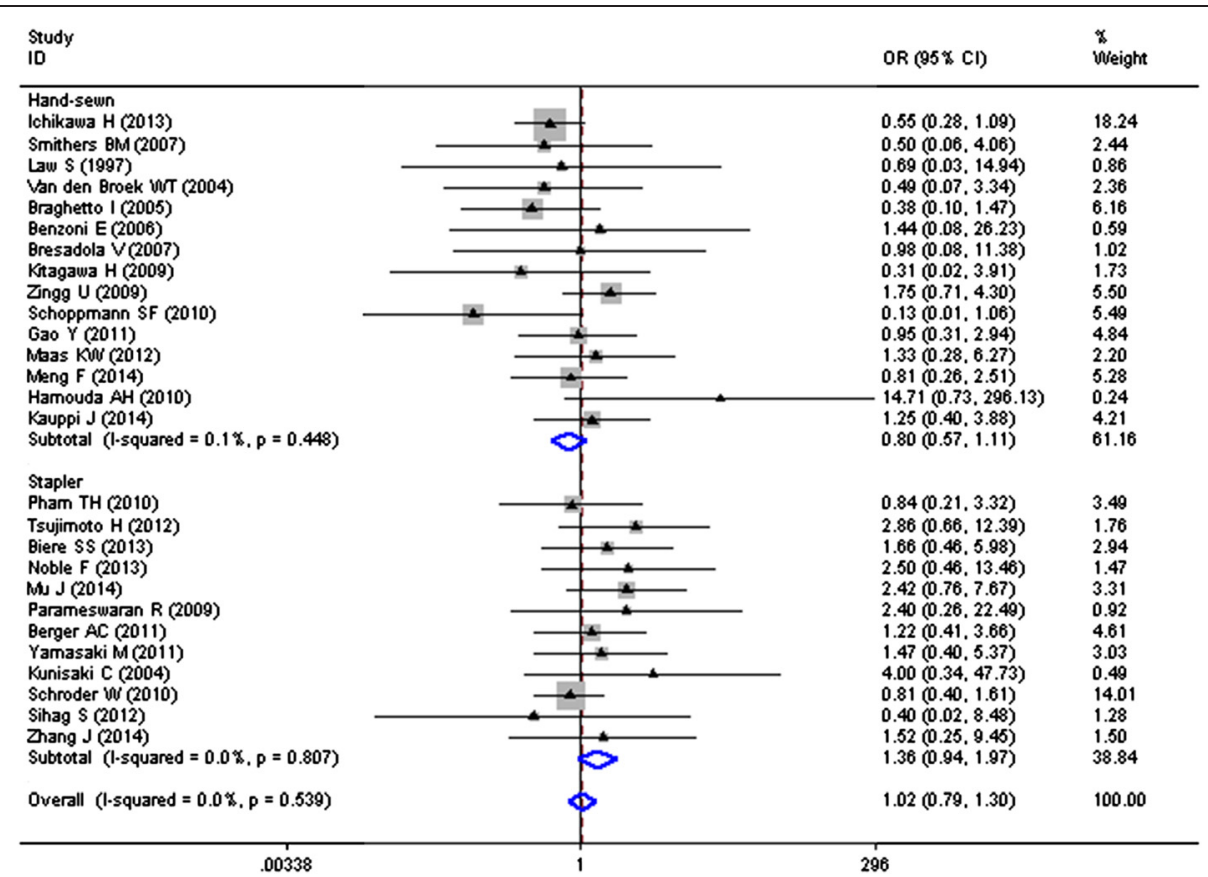

Fig. 4 Anastomotic procedure of MIE and risk of anastomotic leakages (ALs)

anastomotic locations were assumed to have effect on leakage rates in the construction of intrathoracic and cervical esophagogastric anastomosis. In our analysis, we found the frequency of AL occurred in 8.3 and $9.7 \%$ participators in MIE and OE groups, respectively, when performed with cervical esophagogastric anastomosis. However, no significant differences in the occurrence of ALs between the two groups were found when performed with thoracic or cervical esophagogastric anastomosis. Therefore, more proofs were needed to clarify the strengths and weaknesses of each anastomotic location.
We know that esophagogastric anastomoses can be performed via hand-sewn or stapled techniques by using mechanical stapling devices. Mechanical stapled anastomotic techniques, which were first described in 1977 [70], were deemed to have advantages of reduced time and likelihood of esophagogastric anastomotic failure, owing to the relatively ischemic gastric conduit resulting from staple distribution, staple closure, and the more uniform anastomotic tension along the entirety of the anastomosis [71]. Many reports showed that mechanical stapled anastomoses can decrease the rate of leakage

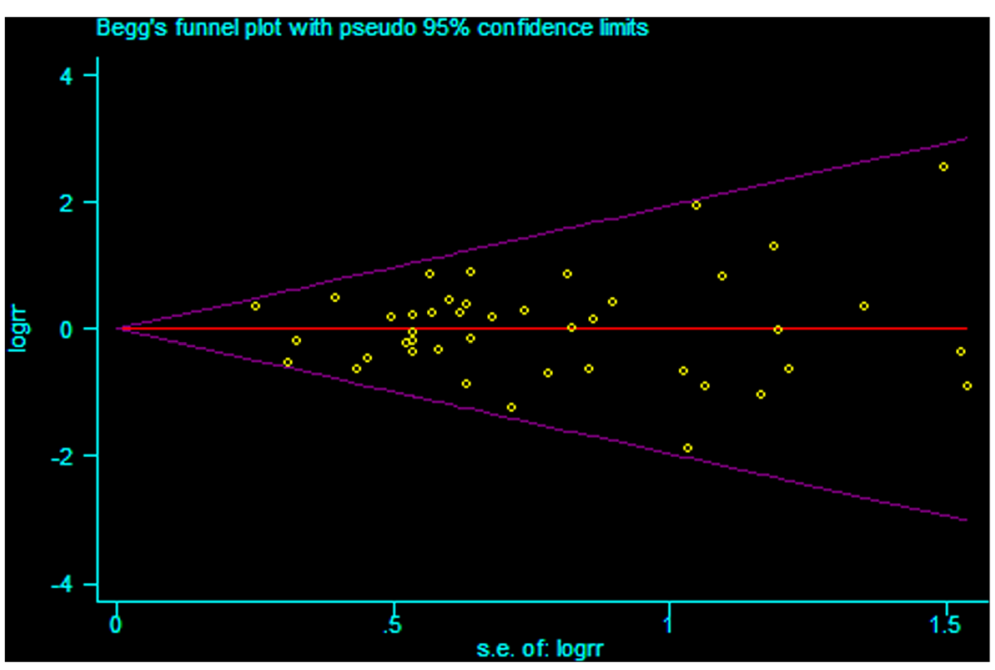

Fig. 5 Begg plot of included studies 
after esophagogastrostomy [72, 73]. In our analysis, we failed to demonstrate a statistically significant difference in anastomotic leak rate after the comparison of MIE and $\mathrm{OE}$ undergoing hand-sewn or stapled technique. This consistent result further partly corroborates the existing evidence that mechanical stapled anastomoses can decrease the rate of leakage after esophagogastrostomy $[72,73]$. The underlying reason may be the similarity in the adequately exposed operative field and level of ischemic gastric conduit. Nevertheless, our results indicated a tendency that the application of MIE could reduce the rate of ALs by hand-sewn anastomoses but increased the rate of ALs by stapled anastomoses. Therefore, there is insufficient evidence to clarify the strengths or weaknesses of MIE in preventing anastomotic leakages after esophagectomy for cancer.

Our meta-analysis has some limitations that might affect the interpretation of the results. First of all, among the included studies, only one was a RCT. The remaining 43 studies included were case-control or cross-sectional studies, which were susceptible to recall and selection biases. Therefore, to some degree, the studies included could not provide better evidence for potential treatment effects/ harms than RCT. There might have been some underreporting of weight and overreporting of height, which might have led to an underestimation of the OR for this association. Secondly, there existed differences in study designs, demographics of participants, standardized protocols, histopathological types, and the characteristics of the tumor (poor tumor differentiation or advanced TNM stage). However, despite the use of appropriate meta-analytic techniques, we are unable to account for these differences, which may result in an overestimation or underestimation of the effect of MIO. Thirdly, unmeasured or residual confounding was likely to be present, such as preoperative nutritional status, intraoperative collateral tissue damage, bleeding, worsening organ failure due to surgical trauma, or difference of surgical techniques among the surgeons in included studies. Finally, we have to admit that patients selected for minimally invasive surgery are more likely to be in early stages of cancer, with smaller tumors and less risk of complications occurrence than patients in late stages.

\section{Conclusions}

Minimally invasive esophagectomy seems to have a significant impact on the reduction in ALs risk due to the introduction of long laparoscopic and thoracoscopic instruments. A systematic review and meta-analysis can help to confirm the superiority.

Currently, there is no evidence to clarify the strengths or weaknesses of MIE in preventing anastomotic leakages after esophagectomy for cancer. A largely randomized, controlled trial should be undertaken to resolve this contentious issue urgently.

\section{Competing interests}

The authors declare that they have no competing interests.

\section{Authors' contributions}

$C Z$, YR, GM, and $X L$ performed statistical analysis and wrote the manuscript. $\mathrm{PL}, J \mathrm{H}$, and $\mathrm{YR}$ conceived of the study, participated in its design and coordination, and helped to draft the manuscript. $Y Y$ and $P L$ revised and edited the manuscript. All authors read and approved the final manuscript.

\section{Authors' information}

Can Zhou and Gang Ma are considered as co-first authors. Yu Ren and Jianjun $\mathrm{He}$ are considered as co-corresponding authors. All authors read and approved the final manuscript.

\section{Acknowledgements}

This work was collectively supported by the Department of Medical Records in the First Affiliated Hospital, Medicine College of Xi'an Jiaotong University.

\section{Author details}

${ }^{1}$ Department of Breast Surgery, the First Affiliated Hospital, Xi'an Jiaotong University, 277 Yanta Western Rd, Xi'an 710061 Shaanxi Province, China. ${ }^{2}$ Department of Translational Medicine Center, the First Affiliated Hospital, Xi'an Jiaotong University, Xi'an 710061 Shaanxi Province, China.

Received: 23 March 2015 Accepted: 27 July 2015

Published online: 04 September 2015

\section{References}

1. Beitler AL, Urschel JD. Comparison of stapled and hand-sewn esophagogastric anastomoses. Am J Surg. 1998;175:337-40.

2. Schweigert M, Dubecz A, Stadlhuber RJ, Muschweck H, Stein HJ. Treatment of intrathoracic esophageal anastomotic leaks by means of endoscopic stent implantation. Interact Cardiovasc Thorac Surg. 2011;12:147-51.

3. Morita M, Nakanoko T, Fujinaka Y, Kubo N, Yamashita N, Yoshinaga K, et al. In-hospital mortality after a surgical resection for esophageal cancer: analyses of the associated factors and historical changes. Ann Surg Oncol. 2011;18:1757-65.

4. Korst RJ, Port JL, Lee PC, Altorki NK. Intrathoracic manifestations of cervical anastomotic leaks after transthoracic esophagectomy for carcinoma. Ann Thorac Surg. 2005;80:1185-90.

5. Weidenhagen R, Hartl WH, Gruetzner KU, Eichhorn ME, Spelsberg F, Jauch KW. Anastomotic leakage after esophageal resection: new treatment options by endoluminal vacuum therapy. Ann Thorac Surg. 2010;90:1674-81.

6. Lorentz T, Fok M, Wong J. Anastomotic leakage after resection and bypass for esophageal cancer: lessons learned from the past. World J Surg. 1989;13:472-7.

7. Hopkins RA, Alexander JC, Postlethwait RW. Stapled esophagogastric anastomosis. Am J Surg. 1984;147:283-7.

8. Law S, Fok M, Chu KM, Wong J. Comparison of hand-sewn and stapled esophagogastric anastomosis after esophageal resection for cancer: a prospective randomized controlled trial. Ann Surg. 1997;226:169-73.

9. Cuschieri A, Shimi S, Banting S. Endoscopic oesophagectomy through a right thoracoscopic approach. J R Coll Surg Edinb. 1992;37:7-11.

10. Depaula AL, Hashiba K, Ferreira EA, de Paula RA, Grecco E. Laparoscopic transhiatal esophagectomy with esophagogastroplasty. Surg LaparosC Endosc Percut Tec. 1995;5:1-5.

11. Willer BL, Worrell SG, Fitzgibbons Jr RJ, Mittal SK. Incidence of diaphragmatic hernias following minimally invasive versus open transthoracic Ivor Lewis McKeown esophagectomy. Hernia. 2012;16:185-90.

12. Kipfmüller K, Naruhn M, Melzer A, Kessler S, Buess G. Endoscopic microsurgical dissection of the esophagus. Results in an animal model. Surg Endosc. 1989;3:63-9.

13. Law S. Minimally invasive techniques for oesophageal cancer surgery. Best Pract Res Clin Gastroenterol. 2006;20:925-40.

14. Pham TH, Perry KA, Dolan JP, Schipper P, Sukumar M, Sheppard BC, et al. Comparison of perioperative outcomes after combined thoracoscopiclaparoscopic esophagectomy and open Ivor-Lewis esophagectomy. Am J Surg. 2010;199:594-8.

15. Biere SS, van Berge Henegouwen MI, Maas KW, Bonavina L, Rosman C, Garcia JR, et al. Minimally invasive versus open oesophagectomy for patients with oesophageal cancer: a multicentre, open-label, randomised controlled trial. Lancet. 2012;379:1887-92. 
16. Lee L, Sudarshan M, Li C, Latimer E, Fried GM, Mulder DS, et al. Costeffectiveness of minimally invasive versus open esophagectomy for esophageal cancer. Ann Surg Oncol. 2013;20:3732-9.

17. Yamamoto M, Weber JM, Karl RC, Meredith KL. Minimally invasive surgery for esophageal cancer: review of the literature and institutional experience. Cancer Control. 2013;20:130-7.

18. Liberati A, Altman DG, Tetzlaff J, Mulrow C, Gøtzsche PC, loannidis JP, et al The PRISMA statement for reporting systematic reviews and meta-analyses of studies that evaluate health care interventions: explanation and elaboration. PLoS Med. 2009;6e1000100.

19. Slim K, Nini E, Forestier D, Kwiatkowski F, Panis Y, Chipponi J. Methodological index for non-randomized studies (MINORS): development and validation of a new instrument. ANZ J Surg. 2003:73:712-6.

20. Egger M, Davey Smith G, Schneider M, Minder C. Bias in meta-analysis detected by a simple, graphical test. BMJ. 1997;315:629-34.

21. Higgins JP, Thompson SG, Deeks JJ, Altman DG. Measuring inconsistency in meta-analyses. BMJ. 2003;327:557-60.

22. Higgins JP, Thompson SG. Quantifying heterogeneity in a meta-analysis. Stat Med. 2002;21:1539-58.

23. Thompson SG, Deeks JJ, Altman DG. Measuring inconsistency in metaanalyses. BMJ. 2003;327:557-60.

24. Nguyen NT, Follette DM, Wolfe BM, Schneider PD, Roberts P, Goodnight Jr JE. Comparison of minimally invasive esophagectomy with transthoracic and transhiatal esophagectomy. Arch Surg. 2000;135:920-5.

25. Kubo N, Ohira M, Yamashita Y, et al. The impact of combined thoracoscopic and laparoscopic surgery on pulmonary complications after radical esophagectomy in patients with resectable esophageal cancer. Anticancer Res. 2014:34:2399-404

26. Braghetto I, Csendes A, Cardemil G, Burdiles P, Korn O, Valladares H. Open transthoracic or transhiatal esophagectomy versus minimally invasive esophagectomy in terms of morbidity, mortality and survival. Surg Endosc. 2006;20:1681-6.

27. Fabian T, Martin JT, McKelvey AA, Federico JA. Minimally invasive esophagectomy: a teaching hospital's first year experience. Dis Esophagus. 2008;21:220-5.

28. Shiraishi T, Kawahara K, Shirakusa T, Yamamoto S, Maekawa T. Risk analysis in resection of thoracic esophageal cancer in the era of endoscopic surgery. Ann Thorac Surg. 2006;81:1083-9.

29. Tsujimoto H, Ono S, Sugasawa H, Ichikura T, Yamamoto J, Hase K. Gastric tube reconstruction by laparoscopy-assisted surgery attenuates postoperative systemic inflammatory response after esophagectomy for esophageal cancer. World J Surg. 2010;34:2830-6.

30. Schröder W, Hölscher AH, Bludau M, Vallböhmer D, Bollschweiler E, Gutschow C. Ivor-Lewis esophagectomy with and without laparoscopic conditioning of the gastric conduit. World J Surg. 2010;34:738-43.

31. Gao Y, Wang Y, Chen L, Zhao Y. Comparison of open three-field and minimally-invasive esophagectomy for esophageal cancer. Interact Cardiovasc Thorac Surg. 2011;12:366-9.

32. Nafteux $P$, Moons J, Coosemans W, Decaluwé H, Decker G, De Leyn P, et al. Minimally invasive oesophagectomy: a valuable alternative to open oesophagectomy for the treatment of early oesophageal and gastrooesophageal junction carcinoma. Eur J Cardiothorac Surg. 2011;40:1455-63. discussion 1463-1464

33. Sundaram A, Geronimo JC, Willer BL, Hoshino M, Torgersen Z, Juhasz A, et al. Survival and quality of life after minimally invasive esophagectomy: a single-surgeon experience. Surg Endosc. 2012;26:168-76.

34. Maas KW, Biere SS, Scheepers JJ, Gisbertz SS, van-der-Peet DL, Cuesta MA. Laparoscopic versus open transhiatal esophagectomy for distal and junction cancer. Rev Esp Enferm Dig. 2012;104:197-202

35. Tsujimoto $H$, Takahata $R$, Nomura $S$, Yaguchi $Y$, Kumano I, Matsumoto $Y$, et al. Video-assisted thoracoscopic surgery for esophageal cancer attenuates postoperative systemic responses and pulmonary complications. Surgery. 2012;151:667-73

36. Mu J, Yuan Z, Zhang B, Li N, Lyu F, Mao Y, et al. Comparative study of minimally invasive versus open esophagectomy for esophageal cancer in a single cancer center. Chin Med J (Engl). 2014;127:747-52

37. Kauppi J, Räsänen J, Sihvo E, Huuhtanen R, Nelskylä K, Salo J. Open versus minimally invasive esophagectomy: clinical outcomes for locally advanced esophageal adenocarcinoma. Surg Endosc. 2014,[Epub ahead of print].
38. Meng F, Li Y, Ma H, Yan M, Zhang R. Comparison of outcomes of open and minimally invasive esophagectomy in 183 patients with cancer. J Thorac Dis. 2014;6:1218-24.

39. Zhang J, Xu M, Guo M, Mei X, Liu C. Analysis of postoperative quality of life in patients with middle thoracic esophageal carcinoma undergoing minimally invasive Ivor-Lewis esophagectomy. Zhonghua Wei Chang Wai Ke Za Zhi. 2014;17:915-9.

40. Li J, Shen $Y$, Tan L, Feng M, Wang H, Xi Y, Wang Q. Is minimally invasive esophagectomy beneficial to elderly patients with esophageal cancer. Surg Endosc. 2015;29:925-930.

41. Javidfar J, Bacchetta M, Yang JA, Miller J, D'Ovidio F, Ginsburg ME, et al. The use of a tailored surgical technique for minimally invasive esophagectomy. J Thorac Cardiovasc Surg. 2012:143:1125-9.

42. Smithers BM, Gotley DC, Martin I, Thomas JM. Comparison of the outcomes between open and minimally invasive esophagectomy. Ann Surg. 2007;245:232-40

43. Kunisaki C, Hatori S, Imada T, Akiyama H, Ono H, Otsuka Y, et al. Videoassisted thoracoscopic esophagectomy with a voice-controlled robot: the AESOP System. Langenbecks Arch Surg. 2009;394:617-21.

44. Osugi H, Takemura M, Higashino M, Sakurai K, Toyokawa T, Tanaka H, et al. A comparison of video-assisted thoracoscopic oesophagectomy and radical lymph node dissection for squamous cell cancer of the oesophagus with open operation. Br J Surg. 2003:90:108-13.

45. Benzoni E, Terrosu G, Bresadola V, Uzzau A, Intini S, Noce L, et al. A comparative study of the transhiatal laparoscopic approach versus laparoscopic gastric mobilisation and right open transthoracic esophagectomy for esophageal cancer management. J Gastrointestin Liver Dis. 2007:16:395-401.

46. Perry KA, Enestvedt CK, Pham T, Welker M, Jobe BA, Hunter JG, et al. Comparison of laparoscopic inversion esophagectomy and open transhiatal esophagectomy for high-grade dysplasia and stage I esophageal adenocarcinoma. Arch Surg. 2009;144:679-84.

47. Hamouda AH, Forshaw MJ, Tsigritis K, Jones GE, Noorani AS, Rohatgi A, et al. Perioperative outcomes after transition from conventional to minimally invasive Ivor-Lewis esophagectomy in a specialized center. Surg Endosc. 2010;24:865-9.

48. Schoppmann SF, Prager G, Langer FB, Riegler FM, Kabon B, Fleischmann E, et al. Open versus minimally invasive esophagectomy: a single-center case controlled study. Surg Endosc. 2010;24:3044-53.

49. Safranek PM, Cubitt J, Booth MI, Dehn TC. Review of open and minimal access approaches to oesophagectomy for cancer. Br J Surg. 2010;97:1845-53.

50. Lee JM, Cheng JW, Lin MT, Huang PM, Chen JS, Lee YC. Is there any benefit to incorporating a laparoscopic procedure into minimally invasive esophagectomy? The impact on perioperative results in patients with esophageal cancer. World J Surg. 2011:35:790-7.

51. Sihag S, Wright CD, Wain JC, Gaissert HA, Lanuti M, Allan JS, et al. Comparison of perioperative outcomes following open versus minimally invasive Ivor Lewis oesophagectomy at a single, high-volume centre. Eur J Cardiothorac Surg. 2012:42:430-7.

52. Kinjo Y, Kurita N, Nakamura F, Okabe H, Tanaka E, Kataoka Y, et al. Effectiveness of combined thoracoscopic-laparoscopic esophagectomy: comparison of postoperative complications and midterm oncological outcomes in patients with esophageal cancer. Surg Endosc. 2012;26:381-90.

53. Noble F, Kelly JJ, Bailey IS, Yaguchi Y, Kumano I, Matsumoto Y, et al. A prospective comparison of totally minimally invasive versus open Ivor Lewis esophagectomy. Dis Esophagus. 2013;26:263-71.

54. Kitagawa H, Akimori T, Okabayashi T, Namikawa T, Sugimoto T, Kobayashi $M$, et al. Total laparoscopic gastric mobilization for esophagectomy. Langenbecks Arch Surg. 2009:394:617-21.

55. Ichikawa H, Miyata G, Miyazaki S, Onodera K, Kamei T, Hoshida T, et al. Esophagectomy using a thoracoscopic approach with an open laparotomic or hand-assisted laparoscopic abdominal stage for esophageal cancer: analysis of survival and prognostic factors in 315 patients. Ann Surg. 2013;257:873-85.

56. Berger AC, Bloomenthal A, Weksler B, Evans N, Chojnacki KA, Yeo CJ, et al. Oncologic efficacy is not compromised, and may be improved with minimally invasive esophagectomy. J Am Coll Surg. 2011;212:560-6.

57. Yamasaki M, Miyata H, Fujiwara Y, Takiguchi S, Nakajima K, Kurokawa Y, et al. Minimally invasive esophagectomy for esophageal cancer: comparative analysis of open and hand-assisted laparoscopic abdominal 
lymphadenectomy with gastric conduit reconstruction. J Surg Oncol. 2011;104:623-8.

58. Law S, Fok M, Chu KM, Wong J. Thoracoscopic esophagectomy for esophageal cancer. Surgery. 1997;122:8-14.

59. Wang H, Feng M, Tan L, Wang Q. Comparison of the short-term quality of life in patients with esophageal cancer after subtotal esophagectomy via videoassisted thoracoscopic or open surgery. Dis Esophagus. 2010;23:408-14.

60. Parameswaran R, Veeramootoo D, Krishnadas R, Cooper M, Berrisford R, Wajed S. Comparative experience of open and minimally invasive esophagogastric resection. World J Surg. 2009;33:1868-75.

61. Saha AK, Sutton CD, Sue-Ling H, Dexter SP, Sarela Al. Comparison of oncological outcomes after laparoscopic transhiatal and open esophagectomy for $\mathrm{T} 1$ esophageal adenocarcinoma. Surg Endosc. 2009;23:119-24.

62. Van den Broek WT, Makay O, Berends FJ, Yuan JZ, Houdijk AP, Meijer S, et al. Laparoscopically assisted transhiatal resection for malignancies of the distal esophagus. Surg Endosc. 2004;18:812-7.

63. Zingg U, McQuinn A, DiValentino D, Esterman AJ, Bessell JR, Thompson SK, et al. Minimally invasive versus open esophagectomy for patients with esophageal cancer. Ann Thorac Surg. 2009;87:911-9.

64. Bresadola V, Terrosu G, Cojutti A, Benzoni E, Baracchini E, Bresadola F. Laparoscopic versus open gastroplasty in esophagectomy for esophageal cancer: a comparative study. Surg Laparosc Endosc Percutan Tech. 2006;16:63-7.

65. Luketich JD, Pennathur A, Awais O, Levy RM, Keeley S, Shende M, et al. Outcomes after minimally invasive esophagectomy: review of over 1000 patients. Ann Surg. 2012;256:95-103.

66. Markar SR, Arya S, Karthikesalingam A, Hanna GB. Technical factors that affect anastomotic integrity following esophagectomy: systematic review and meta-analysis. Ann Surg Oncol. 2013;20:4274-81.

67. Bardini R, Asolati M, Ruol A, Bonavina L, Baseggio S, Peracchia A. Anastomosis. World J Surg. 1994;18:373-8.

68. Walther B, Johansson J, Johnsson F, Von Holstein CS, Zilling T. Cervical or thoracic anastomosis after esophageal resection and gastric tube reconstruction: a prospective randomized trial comparing sutured neck anastomosis with stapled intrathoracic anastomosis. Ann Surg. 2003;238:803-14.

69. Patil PK, Patel SG, Mistry RC, Deshpande RK, Desai PB. Cancer of the esophagus: esophagogastric anastomotic leak-a retrospective study of predisposing factors. J Surg Oncol. 1992:49:163-7.

70. Ravitch MM, Steichen FM. A stapling instrument for end-to-end inverting anastomoses in the gastrointestinal tract. Ann Surg. 1979;189:791-7.

71. Santos RS, Raftopoulos Y, Singh D, DeHoyos A, Fernando HC, Keenan RJ, et al. Utility of total mechanical stapled cervical esophagogastric anastomosis after esophagectomy: a comparison to conventional anastomotic techniques. Surgery. 2004;136:917-25.

72. Valverde A, Hay JM, Fingerhut A, Elhadad A. Manual versus mechanical esophagogastric anastomosis after resection for carcinoma: a controlled trial. French Associations for Surgical Research. Surgery. 1996;120:476-83.

73. Ercan S, Rice TW, Murthy SC, Rybicki LA, Blackstone EH. Does esophagogastric anastomotic technique influence the outcome of patients with esophageal cancer? J Thorac Cardiovasc Surg. 2005;129:623-31.

\section{Submit your next manuscript to BioMed Central and take full advantage of:}

- Convenient online submission

- Thorough peer review

- No space constraints or color figure charges

- Immediate publication on acceptance

- Inclusion in PubMed, CAS, Scopus and Google Scholar

- Research which is freely available for redistribution 